\title{
Corrigendum: Pediatric Flatfeet-A Disease Entity That Demands Greater Attention and Treatment
}

\author{
Philip J. Bresnahan ${ }^{1 *}$ and Mario A. Juanto ${ }^{2}$ \\ ${ }^{1}$ Indian Valley Podiatry Associates, PC, Souderton, PA, United States, ${ }^{2}$ Hospital de Niños Victor J. Vilela, Rosario, Argentina
}

Keywords: pediatric flatfeet, hyperpronation, pes planus, subtalar joint instability, extra-osseous talotarsal stabilization, flat feet

\section{A Corrigendum on:}

OPEN ACCESS

Edited and reviewed by:

Frontiers in Pediatrics,

Frontiers Media SA, Switzerland

*Correspondence:

Philip J. Bresnahan

footdoc_99@yahoo.com

Specialty section:

This article was submitted to

Pediatric Orthopedics,

a section of the journal

Frontiers in Pediatrics

Received: 02 July 2021

Accepted: 08 July 2021

Published: 01 September 2021

Citation:

Bresnahan PJ and Juanto MA (2021)

Corrigendum: Pediatric Flatfeet $-A$

Disease Entity That Demands Greater Attention and Treatment.

Front. Pediatr. 9:735481

doi: 10.3389/fped.2021.735481
Pediatric Flatfeet-A Disease Entity That Demands Greater Attention and Treatment Bresnahan, P. J., and Juanto, M. A. (2020). Front. Pediatr. 8:19. doi: 10.3389/fped.2020.00019

In the original article, we neglected to include a conflict of interest statement (see below).

$\mathrm{PB}$ has no financial interest in Gramedica, but has been reimbursed for travel expenses to speak at seminars (as all speakers are), but received no honoraria while discussing the type of procedure performed in the article. MJ is listed as a clinical instructor for the Graham International Implant Institute.

Reviewer MG is the founder and president of the Graham International Implant Institute, and the company GraMedica that produces the HyProCure ${ }^{\circledR}$ implant, which is used to treat bone misalignment in flat feet.

The authors apologize for this error and state that this does not change the scientific conclusions of the article in any way. The original article has been updated.

Publisher's Note: All claims expressed in this article are solely those of the authors and do not necessarily represent those of their affiliated organizations, or those of the publisher, the editors and the reviewers. Any product that may be evaluated in this article, or claim that may be made by its manufacturer, is not guaranteed or endorsed by the publisher.

Copyright (๑) 2021 Bresnahan and Juanto. This is an open-access article distributed under the terms of the Creative Commons Attribution License (CC BY). The use, distribution or reproduction in other forums is permitted, provided the original author(s) and the copyright owner(s) are credited and that the original publication in this journal is cited, in accordance with accepted academic practice. No use, distribution or reproduction is permitted which does not comply with these terms. 